Trans R Soc Trop Med Hyg. 2011 January ; 105(1): 1-6. doi:10.1016/j.trstmh.2010.09.006.

\title{
Diagnosis of visceral leishmaniasis
}

\author{
Pankaj Srivastava, Anand Dayama, Sanjana Mehrotra, and Shyam Sundar* \\ Department of Medicine, Institute of Medical Sciences, Banaras Hindu University, Varanasi, India
}

\begin{abstract}
Leishmaniasis is a vector-borne disease with up to 350 million people at risk of infection worldwide. Among its different clinical manifestations, visceral is the most severe form. Since clinical features of visceral leishmaniasis (VL) mimic several other common diseases, accurate diagnosis of VL is crucial as the treatment is associated with significant toxicity. Invasive and risky techniques involving demonstration of the parasites in stained preparations from splenic and bone marrow aspirate is still the gold standard for VL diagnosis. Serological tests using rk39 in ELISA or rapid immunochromatographic format, Direct Agglutination Test (DAT), immunoblotting have issues related to a significant proportion of asymptomatic individuals being positive with these tests and their inability to diagnose relapses as these remain positive for several months to years after cure. PCR is the most common molecular technique successfully used for diagnosis and differentiation of species. Through this review we focus extensively on the comparative utilities of the various diagnostic tools currently available for VL, describing in depth their advantages and disadvantages, addressing the recent advances attained in the field. A simple, rapid, non invasive, accurate and cost effective marker of active VL, which can be used in field conditions, is necessary to improve diagnosis of VL.
\end{abstract}

\section{Keywords}

Visceral leishmaniasis; Diagnosis; rK39; Polymerase chain reaction; Sensitivity; Specificity

\section{Introduction}

Visceral leishmaniasis (VL), is a vector-borne disease caused by replication of parasites in macrophages, mononuclear phagocytic system. It is caused by the Leishmania donovani complex, which includes $L$. donovani and $L$. infantum. It is endemic in large areas of the tropics, subtropics and the Mediterranean Basin. VL is a systemic disease and is fatal if left untreated. The transmission characteristics of VL differs in different geographical regions; in the Mediterranean Basin, Brazil and parts of Africa, the dog is the main reservoir and VL is zoonotic; while in the Indian subcontinent and parts of Africa, it is anthroponotic. ${ }^{1}$

\footnotetext{
(C) 2010 Royal Society of Tropical Medicine and Hygiene. Published by Elsevier Ltd. All rights reserved.

* Corresponding Author: Prof. Shyam Sundar Tel.: +91 542 2369632; drshyamsundar@hotmail.com. Authors' Contributions: PS and AD conceived the idea of writing the review. PS, AD, SS and SM collected and organised the data and drafted the manuscript. All authors critically read, edited and approved the final manuscript. SS is guarantor of the paper.

Publisher's Disclaimer: This is a PDF file of an unedited manuscript that has been accepted for publication. As a service to our customers we are providing this early version of the manuscript. The manuscript will undergo copyediting, typesetting, and review of the resulting proof before it is published in its final citable form. Please note that during the production process errors may be discovered which could affect the content, and all legal disclaimers that apply to the journal pertain.

Conflicts of Interest: None declared

Ethical approval: Not required
} 
Post kala-azar dermal leishmaniasis (PKDL) is a sequel of VL, characterized by amacular, maculo-papular or nodular rash and is frequently observed in Sudan and the Indian subcontinent. $^{2}$

Clinical features of VL can be easily mistaken for other febrile illnesses such as malaria and enteric fever. Reliable laboratory methods become mandatory for accurate diagnosis. Early case detection followed by adequate treatment is central to the control of VL.3,4 Patient management, screening of asymptomatic infections, surveillance including verification of elimination, and epidemiological studies are some of the areas where diagnostic tests play a major role. Ideally, a test should make the distinction between acute disease and asymptomatic infection, as most of the antileishmanial drugs are toxic. Moreover, such tests should be highly sensitive and specific, simple and affordable, but unfortunately some commonly used tests like rK39 immunochromatographic strip test (ICT) and Direct Agglutination Test (DAT) carry some significant disadvantages: the inability to differentiate between clinically active and asymptomatic infections and showing positive long after cure. Molecular diagnostic tools like PCR and real-time PCR are quite sensitive and specific but are cumbersome to perform and have a high cost. DNA-based tests are available in strip formats but these cannot be used in the field. ${ }^{5}$ In Latin America where VL is zoonotic, rK39-ICT is widely used for diagnosis in humans, and has clear advantages over the Indirect Fluorescent Antibody Test (IFAT) or ELISA based tests.6 The DAT assay has shown similar diagnostic performance but is not as user-friendly as the rK396. A study from Sudan compared the diagnostic performance of rK39 and DAT for VL both qualitatively and semiquantitatively and recommended the combined application of these two tests for optimizing diagnosis and simultaneously assessing the magnitude of immune response to $L$. donovani infection. ${ }^{7}$ Qualitatively both $\mathrm{rK} 39$ and DAT demonstrated comparable reliability for VL detection (sensitivity $=96 \%$ and specificity $=98.7 \%$ or $99.3 \%)^{7}$

\section{Existing diagnostic methods for diagnosis of VL Parasitological Diagnosis}

Parasitological diagnosis remains the gold standard in the diagnosis of leishmaniasis because of its high specificity. ${ }^{8}$ The amastigote forms (called LD bodies) can be seen in tissue smears from lymph nodes, bone marrow or spleen. In preparations stained with Giemsa or Leishman stain, the cytoplasm appears pale blue, with a relatively large nucleus that stains red. In the same plane as the nucleus, but at a right angle to it, is a deep red or violet rod-like body called a kinetoplast. Splenic smears have the sensitivity of $93.1-98.7 \% .{ }^{9-} 11$ Bone marrow and the lymph node smears have lower sensitivity ranging from 52-85\%11 and 52$58 \% 9,10$ respectively. Bone marrow aspiration (BMA) or splenic aspiration are painful and risky techniques. Serious or fatal bleeding after splenic aspirate is not uncommon, however, in skilled and experienced hands, serious bleeding is rare. At our treatment centre (Kala azar Medical Research Centre, Muzaffarpur, Bihar, India), fatal bleeding has occurred only twice in 9612 splenic aspirate procedures performed over the last 10 years. 14 The use of microscopy in the diagnosis of VL offers the benefits of high specificity and the possibility of grading the parasite on a logarithmic scale (0-6+) in splenic smears.13 But like all microscopic procedures it suffers from variability of detection sensitivity and the inevitable need for an expert microscopist. Culture, too, suffers from the same deficiencies and the tedious, time consuming nature of the technique and the high cost are prohibitive and thus, except in dedicated research laboratories, it is seldom used for clinical diagnosis. In a modification in the form of microtitre culture, sensitive and reproducible detection of parasites was possible using buffy coat (WBC rich layer) and peripheral blood mononuclear cells (PBMC) isolated from patient blood.12 Leishmania strains can be maintained as promastigotes in artificial culture medium. The culture media used may be biphasic (NovyMcNeal Nicolle medium and Tobies medium) for conversion of amastigotes to 
promastigotes while monophasic medium (Schneider's insect medium, M199, or Grace's medium) is preferred for amplifying parasite number.

\section{Serological Diagnosis}

The serological diagnosis is based on the presence of specific humoral response. ${ }^{8}$ A wide range of serological methods varying in sensitivity and specificity are available for the diagnosis of VL. These serological methods can be grouped into non-specific and specific tests.

Non specific tests-Tests like formal gel test have been in use in the past but should be abandoned because of their poor specificity and sensitivity. ${ }^{8}$

Specific tests-Indirect Fluorescent Antibody Test (IFAT): The test is based on detecting antibodies, which are demonstrated in the very early stages of infection and are undetectable six to nine months after cure. If the antibodies persist in low titres, it is an indication of a probable relapse. It is sensitive (96\%) and specific (98\%) but the requirement of sophisticated laboratory conditions prohibit its application in the field. ${ }^{15}$

Enzyme Linked Immunosorbent Assay (ELISA)_ELISA has been used in the serodiagnosis of VL. Sensitivity and specificity of ELISA depends upon the antigen used. Most promising results are shown by antigen rk39 with sensitivity and specificity of $100 \%$ and $96 \%$ respectively. ${ }^{16}$ The antibody titres to this antigen directly correlate with active disease and have potential in monitoring the chemotherapy and in predicting the clinical relapse. ${ }^{17}$ In addition, rK39 ELISA has a high diagnostic and prognostic utility in HIVinfected patients. ${ }^{18}$ Due to the requirement of skilled personnel, sophisticated equipment and electricity, ELISA is not used in the endemic regions for the diagnosis of VL.

Immunoblotting-Provides detailed antibody responses to various leishmanial antigens. This test is more sensitive than IFAT and ELISA, but expensive and time consuming. It also requires considerable skill and is therefore only sparingly used in the diagnosis of VL.

Direct Agglutination Test (DAT)-In this test, Coomassie brilliant blue stained whole promastigotes are incubated with sera of the patients and agglutination observed after an overnight incubation. It is a highly specific, sensitive, inexpensive and simple test. Initially, aqueous antigen was used but it had the drawback of cold chain requirement, and short life. Now, freeze dried antigen has been developed which can be transported at ambient temperature. In a meta-analysis of studies using DAT, it had sensitivity and specificity estimates of $94.8 \%$ (95\% confidence intervals (CI), 92.7-96.4) and $85.9 \%$ (95\% CI, 72.393.4), respectively. ${ }^{19}$ However, the major disadvantage of DAT is the need of multiple pipetting, relatively long incubation time, high cost of antigen and limited production facility of quality controlled antigen in two European laboratories.20,21 As with any antibody based test, DAT remains positive for a long time after the disease is cured, thus cannot be used as a test of cure or for diagnosis of relapses. Furthermore, about $20-30 \%$ of healthy individuals living in the endemic areas test positive with DAT, and an illness mimicking VL might be mistaken for VL if DAT is positive in this particular individual.22

Immunochromatographic (ICT) strip test-Immunochromatographic strips using K39 antigen have become popular in recent years. K39 antigen contains 39 amino acids encoded by a 117 base pairs gene encoded in the highly conserved kinesin region of L. chagasi. In micro-ELISA format this antigen showed remarkably high sensitivity. Using its recombinant product, an immunochromatographic based strip test has been developed in which rK39 is fixed on a nitrocellulose paper, and colloidal gold-protein A is used for detection. A drop of 
serum or blood obtained by finger prick is smeared over the tip of the strips and dipped in a small amount of buffer, with the results read within 15 minutes. In the initial clinical evaluation $100 \%$ sensitivity and $98 \%$ specificity was observed. ${ }^{23}$ The rK39 strip test has been found highly sensitive and a reliable indicator of kala-azar.18,24-26 In a meta-analysis of rK39 strip test studies, the results were quite uniform with very high sensitivity $98.4-$ $100 \%$ and specificity $81.2-96.4 \% .{ }^{27}$ In Sudan, however, the sensitivity $(69.2-85.6 \%)$ of strip tests has been low compared with other regions. However, a new version produced by DiaMed AG, (Cressier sur Morat, Switzerland) has been reported to have satisfactory results from Sudan. Unfortunately the market of strips in disease endemic countries remains unregulated, and several formats are available which have not been evaluated for their performance. ICT suffers from the same disadvantage as DAT: being positive in a significant proportion of healthy individuals in endemic regions and for long periods after cure of VL. TDR/WHO are carrying out a worldwide multicenter evaluation of commercially available rapid tests for VL.

Antigen Detection-The antigen detection is an excellent method of diagnosing an infection. It is more specific than antibody-based immunodiagnostic tests. ${ }^{28,29}$ Antigen levels are expected to broadly correlate with the parasite load. This method of diagnosis should be a better alternative to the antibody detection, particularly in HIV-VL coinfection, where antibody response is very poor. Two polypeptide fractions of $72-75 \mathrm{kDa}$ and $123 \mathrm{kDa}$ were detected in the urine of kala-azar patients. The sensitivity of the $72-75 \mathrm{kDa}$ fractions were $96 \%$ and the specificity was $100 \%$. These antigens were not detectable within three weeks of successful antileishmanial treatment, suggesting that the test has a very good prognostic value. ${ }^{28}$ Another urinary leishmanial antigen, a low-molecular-weight, heatstable carbohydrate was detected in the urine of VL patients. ${ }^{30}$ An agglutination test to detect this antigen has been evaluated extensively in clinical trials, using urine collected from well-defined cases and controls from endemic and non-endemic regions. This test showed $79.1-94.1 \%$ specificity and sensitivity of $60.4-71.6 \%$ in India. ${ }^{27}$ However, the sensitivity of this test was low in clinically suspected patients. ${ }^{27,31}$ Efforts are being made to improve the performance of this technique, as it holds promise as a test of cure, for which none of the current serological tests can be employed.

Molecular Diagnosis-PCR-based assays form the mainstay of molecular diagnosis especially for HIV-VL coinfections, 32,33 with primers targeting several multicopy genes, e.g., rRNA genes, kinetoplast DNA (kDNA) minicircles. ${ }^{34-} 37$ A comparative overview of sensitivities and specificities of various PCR based diagnostic assays targeting different regions of leishmania genome has been presented in Table 1. A recent comparative clinical study in Italy between conventional microbiologic techniques and a leishmania speciesspecific PCR assay, using peripheral blood and bone marrow aspirate samples had shown the sensitivities of the leishmania species-specific PCR to be 95.7\% for BMA and 98.5\% for peripheral blood samples versus sensitivities of $76.2 \%, 85.5 \%$, and $90.2 \%$ for BMA isolation, serologic testing, and microscopic examination of bone marrow biopsy specimens, respectively. ${ }^{38}$ In PCR screening of blood samples of suspected cases of VL, sensitivity ranging from around $70 \% 39,40$ to around $100 \%^{36,41-43}$ has been reported. PCR from blood samples obviate the cumbersome and risky process of bone marrow and splenic aspiration. Recently epitope specific PCR and oligochromatographic dipstick assay has been reported for VL and PKDL detection with sensitivity to detect less than one parasite.5,44 Real-time PCR has made quantification of parasite burden possible, with a high degree of complexspecific diagnostic accuracy for clinical samples. ${ }^{45}$ Quantitative nucleic acid sequence-based amplification (QT-NASBA) detects RNA in a background of DNA and may thus serve to measure viable parasites which might significantly increase assay sensitivity and decrease required sample volume. ${ }^{46}$ In a recent report from Kenya the Leishmania OligoC-TesT 
showed a sensitivity of $96.4 \%$ and a specificity of $88.8 \%$, while the sensitivity and specificity of the NASBA-OC were $79.8 \%$ and $100 \%$, respectively. These findings indicate high sensitivity of the Leishmania OligoC-TesT on blood while the NASBA-OC is a better marker for active disease. ${ }^{47}$ The sensitivity of PCR using conjunctival swab (CS) as a sampling method for VL diagnosis by PCR of asymptomatic dogs was found $90 \%$ by kDNA primer and $83.3 \%$ by internal transcribed spacer 1 (ITS1) primer. On the other hand, for blood samples, the positivity of ITS1 PCR was significantly higher than the one obtained by the kDNA PCR-hybridization, indicating that sensitivity of PCR methods can vary according to the biological sample examined. ${ }^{48}$

Reverse transcriptase-loop-mediated isothermal amplification (RT-LAMP) assay, based on nucleic acids, was recently developed as a point-of-care diagnostic tool. Amplification was visualized by the pre-amplification addition of fluorescent detection reagent (FDR) and a simple UV lamp. By using a reverse-transcriptase step, the system detected infections between 10 and 100 parasites per $\mathrm{mL}$. The assay was tested on a range of nucleic acid extracts from Leishmania species, VL patients from Sudan, and cutaneous leishmaniasis (CL) patients from Suriname. The sensitivity of RT-LAMP from the blood of VL patients was $83 \% .{ }^{49}$

\section{Diagnosis of HIV-VL coinfection}

VL is an important opportunistic infection in AIDS patients and atypical clinical presentations of VL in HIV-infected patients pose a considerable diagnostic challenge. In fact, the clinical symptoms of fever, splenomegaly, and hepatomegaly is found in less than half of such patients, though more so in patients with low CD4 counts (less than 50CD4 cells/mm3)50, 51. In these patients, leishmaniasis can present with gastrointestinal involvement (stomach, duodenum, or colon); ascites; pleural or pericardial effusion; involvement of lungs, tonsils, and skin; and even as widely disseminated disease51. The diagnostic principles remain essentially the same as those for non-HIV-infected patients. The presence of amastigotes may be demonstrated in buffy coat preparation. Sometimes the presence of amastigotes in unusual sites may be demonstrated (e.g., amastigotes may be present in specimens from bronchoalveolar lavage, pleural fluid, or biopsy specimens from the gastrointestinal tract)14. For HIV patients, the sensitivity of antibody- based immunologic tests like the IFA test and ELISA is low. Since the parasite load is quite heavy in these patients, the presence of leishmania amastigotes in the bone marrow can often be demonstrated, but there are well-described instances in the literature where amastigotes were not demonstrable in bone marrow, though they were found at unexpected locations like the stomach, the colon, or the lungs. PCR analysis of the whole blood or its buffy coat preparation may prove a useful screening test for these patients, obviating the need for traumatic procedures.

Table 2 presents a concise summary and features of all the described techniques commonly used for VL diagnosis.

\section{Conclusions}

Accurate diagnosis of VL still remains a problem for clinicians and coordinators of kala-azar control programs. Though the gold standard remains the demonstration of parasites, it has several disadvantages and thus diagnosis in field is delayed. Antibody based diagnosis, like rK39 strip test is being popularly used world over in the endemic countries despite their inherent disadvantage of being positive in significant proportion of healthy individuals, and remaining positive for long periods after cure. DAT based on whole promastigotes of $L$. donovani or $L$. infantum and the rK39-ICT are the two serological tests used widely for the diagnosis of VL 52-54. There is an urgent need to develop a marker of the active diseases, 
urine based latex agglutination test had all the qualities to detect only active patients and quickly turning negative after a successful response, however its low sensitivity needs to be improved. Molecular-biology-based assays for detecting parasite DNA have been developed; but none have become popular in field diagnosis.

\section{Box 1. Search criteria, data extraction and quality assessment}

\section{Search Criteria}

We searched Medline through PubMed (http://www.ncbi.nlm.nih.gov/pubmed/) for articles on the diagnosis of VL. Methods compared were microscopy, direct agglutination test (DAT) rK39 immunochromatographic (ICT) assay, ELISA used on serum or blood samples and PCR assay for VL diagnosis. The search terms were 'visceral leishmaniasis', 'kala-azar', with 'diagnostic accuracy', 'sensitivity', 'specificity'. This search generated 384 papers, which we subsequently combined with the search terms 'DAT', 'ELISA', 'ICT dipstick' and 'PCR'. Additional studies were identified through back tracing of reference lists and subsequent reports from the same longitudinal studies.

\section{Data extraction and quality assessment}

We abstracted information from published journals, compared and summarized their sensitivity and specificity along with their merits and demerits of different assays. For quality assessment we took into account different diagnostic markers, their field evaluations and the role of diagnostic tools in treatment failure.

\section{Acknowledgments}

The authors would like to thank all the research scholars working in Infectious Disease Research Laboratory, Department of Medicine, IMS, BHU.

Funding: This work was supported by NIAID, NIH Grant Number: 1P50AI074321-01

\section{References}

1. Alvar J, Canavate C, Molina R, Moreno J, Nieto J. Canine leishmaniasis. Adv Parasitol 2004;57:188. [PubMed: 15504537]

2. Zijlstra EE, Musa AM, Khalil EA, el-Hassan IM, el-Hassan AM. Post-kalaazar dermal leishmaniasis. Lancet Infect Dis 2003;3:87-98. [PubMed: 12560194]

3. Boelaert M, Criel B, Leeuwenburg J, Van Damme W, Le Ray D, Van der Stuyft P. Visceral leishmaniasis control: a public health perspective. Trans R Soc Trop Med Hyg 2000;94:465-71. [PubMed: 11132368]

4. Davies CR, Kaye P, Croft SL, Sundar S. Leishmaniasis: new approaches to disease control. BMJ 2003;326:377-82. [PubMed: 12586674]

5. Deborggraeve S, Laurent T, Espinosa D, Van der Auwera G, Mbuchi M, Wasunna M, et al. A simplified and standardized polymerase chain reaction format for the diagnosis of leishmaniasis. J Infect Dis 2008;198:1565-72. [PubMed: 18816188]

6. Romero GA, Boelaert M. Control of visceral leishmaniasis in Latin America-a systematic review. PLoS Negl Trop Dis 2010;4:e584. [PubMed: 20098726]

7. Mansour D, Abass EM, Mahamoud A, el Harith A. Qualitative and semi-quantitative comparison of an rK39 strip test and direct agglutination test for detection of anti-Leishmania donovani antibodies in the Sudan. Iran J Immunol 2009;6:208-15. [PubMed: 20054109]

8. Herwaldt BL. Leishmaniasis. Lancet 1999;354:1191-9. [PubMed: 10513726]

9. Zijlstra EE, Ali MS, el-Hassan AM, el-Toum IA, Satti M, Ghalib HW, et al. Kala-azar: a comparative study of parasitological methods and the direct agglutination test in diagnosis. Trans $\mathrm{R}$ Soc Trop Med Hyg 1992;86:505-7. [PubMed: 1475815] 
10. Siddig M, Ghalib H, Shillington DC, Petersen EA. Visceral leishmaniasis in the Sudan: comparative parasitological methods of diagnosis. Trans R Soc Trop Med Hyg 1988;82:66-8. [PubMed: 3176153]

11. Ho EA, Soong TH, Li Y. Comparative merits of sternum, spleen and liver punctures in the study of human visceral leishmaniasis. Trans R Soc Trop Med Hyg 1948;41:629-36. [PubMed: 18912189]

12. Maurya RS, Mehrotra S, Prajapati VK, Nylén S, Sacks DL, Sundar S. Evaluation of Blood agar micro-titer plates for culturing Leishmania parasites to titrate the parasite burden in spleen and peripheral blood of VL patients. J Clin Microbiol 2010;48:1932-4. [PubMed: 20335419]

13. Chulay JD, Bryceson AD. Quantitation of amastigotes of Leishmania donovani in smears of splenic aspirates from patients with visceral leishmaniasis. Am J Trop Med Hyg 1983;32:475-9. [PubMed: 6859397]

14. Sundar S, Rai M. Laboratory diagnosis of visceral leishmaniasis. Clin Diagn Lab Immunol 2002;9:951-8. [PubMed: 12204943]

15. Sassi A, Louzir H, Ben Salah A, Mokni M, Ben Osman A, Dellagi K. Leishmanin skin test lymphoproliferative responses and cytokine production after symptomatic or asymptomatic Leishmania major infection in Tunisia. Clin Exp Immunol 1999;116:127-32. [PubMed: 10209516]

16. Palatnik-de-Sousa CB, Gomes EM, Paraguai-de-Souza E, Palatnik M, Luz K, Borojevic R. Leishmania donovani: titration of antibodies to the fucosemannose ligand as an aid in diagnosis and prognosis of visceral leishmaniasis. Trans R Soc Trop Med Hyg 1995;89:390-3. [PubMed: 7570874]

17. Kumar R, Pai K, Pathak K, Sundar S. Enzyme-linked immunosorbent assay for recombinant K39 antigen in diagnosis and prognosis of Indian visceral leishmaniasis. Clin Diagn Lab Immunol 2001;8:1220-4. [PubMed: 11687466]

18. Houghton RL, Petrescu M, Benson DR, Skeiky YA, Scalone A, Badaro R, et al. A cloned antigen (recombinant K39) of Leishmania chagasi diagnostic for visceral leishmaniasis in human immunodeficiency virus type 1 patients and a prognostic indicator for monitoring patients undergoing drug therapy. J Infect Dis 1998;177:1339-44. [PubMed: 9593022]

19. Chappuis F, Rijal S, Soto A, Menten J, Boelaert M. A meta-analysis of the diagnostic performance of the direct agglutination test and rK39 dipstick for visceral leishmaniasis. BMJ 2006;333:723. [PubMed: 16882683]

20. Gari-Toussaint M, Lelievre A, Marty P, Le Fichoux Y. Contribution of serological tests to the diagnosis of visceral leishmaniasis in patients infected with the human immunodeficiency virus. Trans R Soc Trop Med Hyg 1994;88:301-2. [PubMed: 7974668]

21. Schallig HD, Schoone GJ, Kroon CC, Hailu A, Chappuis F, Veeken H. Development and application of 'simple' diagnostic tools for visceral leishmaniasis. Med Microbiol Immunol 2001;190:69-71. [PubMed: 11770114]

22. Sundar S, Singh RK, Maurya R, Kumar B, Chhabra A, Singh V, et al. Serological diagnosis of Indian visceral leishmaniasis: direct agglutination test versus rK39 strip test. Trans R Soc Trop Med Hyg 2006;100:533-7. [PubMed: 16325874]

23. Sundar S, Reed SG, Singh VP, Kumar PC, Murray HW. Rapid accurate field diagnosis of Indian visceral leishmaniasis. Lancet 1998;351:563-5. [PubMed: 9492776]

24. Burns JM Jr. Shreffler WG, Benson DR, Ghalib HW, Badaro R, Reed SG. Molecular characterization of a kinesin-related antigen of Leishmania chagasi that detects specific antibody in African and American visceral leishmaniasis. Proc Natl Acad Sci U S A 1993;90:775-9. [PubMed: 8421715]

25. Singh S, Gilman-Sachs A, Chang KP, Reed SG. Diagnostic and prognostic value of K39 recombinant antigen in Indian leishmaniasis. J Parasitol 1995;81:1000-3. [PubMed: 8544037]

26. Singh S, Kumari V, Singh N. Predicting kala-azar disease manifestations in asymptomatic patients with latent Leishmania donovani infection by detection of antibody against recombinant K39 antigen. Clin Diagn Lab Immunol 2002;9:568-72. [PubMed: 11986261]

27. Boelaert M, El-Safi S, Hailu A, Mukhtar M, Rijal S, Sundar S, et al. Diagnostic tests for kala-azar: a multi-centre study of the freeze-dried DAT, rK39 strip test and KAtex in East Africa and the Indian subcontinent. Trans R Soc Trop Med Hyg 2008;102:32-40. [PubMed: 17942129] 
28. De Colmenares M, Portus M, Riera C, Gallego M, Aisa MJ, Torras S, et al. Short report: detection of 72-75-kD and 123-kD fractions of Leishmania antigen in urine of patients with visceral leishmaniasis. Am J Trop Med Hyg 1995;52:427-8. [PubMed: 7539596]

29. Vinayak VK, Mahajan D, Sobti RC, Singla N, Sundar S. Anti-66 kDa antileishmanial antibodies as specific immunodiagnostic probe for visceral leishmaniasis. Indian J Med Res 1994;99:109-14. [PubMed: 8063345]

30. Sarkari B, Chance M, Hommel M. Antigenuria in visceral leishmaniasis: detection and partial characterisation of a carbohydrate antigen. Acta Trop 2002;82:339-48. [PubMed: 12039673]

31. Rijal S, Boelaert M, Regmi S, Karki BM, Jacquet D, Singh R, et al. Evaluation of a urinary antigen-based latex agglutination test in the diagnosis of kala-azar in eastern Nepal. Trop Med Int Health 2004;9:724-9. [PubMed: 15189464]

32. De Doncker S, Hutse V, Abdellati S, Rijal S, Singh Karki BM, Decuypere S, et al. A new PCRELISA for diagnosis of visceral leishmaniasis in blood of HIV-negative subjects. Trans R Soc Trop Med Hyg 2005;99:25-31. [PubMed: 15550258]

33. Cruz I, Morales MA, Noguer I, Rodriguez A, Alvar J. Leishmania in discarded syringes from intravenous drug users. Lancet 2002;359:1124-5. [PubMed: 11943264]

34. Attar ZJ, Chance ML, el-Safi S, Carney J, Azazy A, El-Hadi M, et al. Latex agglutination test for the detection of urinary antigens in visceral leishmaniasis. Acta Trop 2001;78:11-6. [PubMed: 11164745]

35. Santos-Gomes G, Gomes-Pereira S, Campino L, Araujo MD, Abranches P. Performance of immunoblotting in diagnosis of visceral Leishmaniasis in human immunodeficiency virus Leishmania sp. coinfected patients. J Clin Microbiol 2000;38:175-8. [PubMed: 10618083]

36. El Tai NO, El Fari M, Mauricio I, Miles MA, Oskam L, El Safi SH, et al. Leishmania donovani: intraspecific polymorphisms of Sudanese isolates revealed by PCR-based analyses and DNA sequencing. Exp Parasitol 2001;97:35-44. [PubMed: 11207112]

37. Pizzuto M, Piazza M, Senese D, Scalamogna C, Calattini S, Corsico L, et al. Role of PCR in diagnosis and prognosis of visceral leishmaniasis in patients coinfected with human immunodeficiency virus type 1. J Clin Microbiol 2001;39:357-61. [PubMed: 11136800]

38. Antinori S, Calattini S, Longhi E, Bestetti G, Piolini R, Magni C, et al. Clinical use of polymerase chain reaction performed on peripheral blood and bone marrow samples for the diagnosis and monitoring of visceral leishmaniasis in HIV-infected and HIV-uninfected patients: a single-center, 8-year experience in Italy and review of the literature. Clin Infect Dis 2007;44:1602-10. [PubMed: 17516404]

39. Osman OF, Oskam L, Zijlstra EE, Kroon NC, Schoone GJ, Khalil ET, et al. Evaluation of PCR for diagnosis of visceral leishmaniasis. J Clin Microbiol 1997;35:2454-7. [PubMed: 9316888]

40. Adhya S, Chatterjee M, Hassan MQ, Mukherjee S, Sen S. Detection of Leishmania in the blood of early kala-azar patients with the aid of the polymerase chain reaction. Trans R Soc Trop Med Hyg 1995;89:622-4. [PubMed: 8594675]

41. Salotra P, Sreenivas G, Pogue GP, Lee N, Nakhasi HL, Ramesh V, et al. Development of a species-specific PCR assay for detection of Leishmania donovani in clinical samples from patients with kala-azar and post-kala-azar dermal leishmaniasis. J Clin Microbiol 2001;39:849-54. [PubMed: 11230394]

42. Cruz I, Canavate C, Rubio JM, Morales MA, Chicharro C, Laguna F, et al. A nested polymerase chain reaction (Ln-PCR) for diagnosing and monitoring Leishmania infantum infection in patients co-infected with human immunodeficiency virus. Trans R Soc Trop Med Hyg 2002;96(Suppl 1):S185-9. [PubMed: 12055836]

43. Bossolasco S, Gaiera G, Olchini D, Gulletta M, Martello L, Bestetti A, et al. Real-time PCR assay for clinical management of human immunodeficiency virus-infected patients with visceral leishmaniasis. J Clin Microbiol 2003;41:5080-4. [PubMed: 14605142]

44. Arora SK, Gupta S, Bhardwaj S, Sachdeva N, Sharma NL. An epitope-specific PCR test for diagnosis of Leishmania donovani infections. Trans R Soc Trop Med Hyg 2008;102:41-5. [PubMed: 17888473] 
45. Wortmann G, Hochberg L, Houng HH, Sweeney C, Zapor M, Aronson N, et al. Rapid identification of Leishmania complexes by a real-time PCR assay. Am J Trop Med Hyg 2005;73:999-1004. [PubMed: 16354801]

46. Reithinger R, Dujardin JC. Molecular diagnosis of leishmaniasis: current status and future applications. J Clin Microbiol 2007;45:21-5. [PubMed: 17093038]

47. Basiye FL, Mbuchi M, Magiri C, Kirigi G, Deborggraeve S, Schoone GJ, et al. Sensitivity and specificity of the Leishmania OligoC-TesT and NASBA-oligochromatography for diagnosis of visceral leishmaniasis in Kenya. Trop Med Int Health 2010;15:806-810. [PubMed: 20487428]

48. Leite RS, Ferreira Sde A, Ituassu LT, de Melo MN, de Andrade AS. PCR diagnosis of visceral leishmaniasis in asymptomatic dogs using conjunctival swab samples. Vet Parasitol 2010;170:201-6. [PubMed: 20227834]

49. Adams ER, Schoone GJ, Ageed AF, Safi SE, Schallig HD. Development of a reverse transcriptase loop-mediated isothermal amplification (LAMP) assay for the sensitive detection of Leishmania parasites in clinical samples. Am J Trop Med Hyg 2010;82:591-6. [PubMed: 20348505]

50. Albrecht H. Leishmaniosis--new perspectives on an underappreciated opportunistic infection. AIDS 1998;12:2225-6. [PubMed: 9833865]

51. Alvar J, Canavate C, Gutierrez-Solar B, Jimenez M, Laguna F, Lopez-Velez R, et al. Leishmania and human immunodeficiency virus coinfection: the first 10 years. Clin Microbiol Rev 1997;10:298-319. [PubMed: 9105756]

52. Chappuis F, Sundar S, Hailu A, Ghalib H, Rijal S, Peeling RW, et al. Visceral leishmaniasis: what are the needs for diagnosis, treatment and control? Nat Rev Microbiol 2007;5:873-82. [PubMed: 17938629]

53. Chappuis F, Rijal S, Jha UK, Desjeux P, Karki BM, Koirala S, et al. Field validity, reproducibility and feasibility of diagnostic tests for visceral leishmaniasis in rural Nepal. Trop Med Int Health 2006;11:31-40. [PubMed: 16398753]

54. Meredith SE, Kroon NC, Sondorp E, Seaman J, Goris MG, van Ingen CW, et al. Leish-KIT, a stable direct agglutination test based on freeze-dried antigen for serodiagnosis of visceral leishmaniasis. J Clin Microbiol 1995;33:1742-5. [PubMed: 7665640]

55. Nuzum E, White F 3rd, Thakur C, Dietze R, Wages J, Grogl M, et al. Diagnosis of symptomatic visceral leishmaniasis by use of the polymerase chain reaction on patient blood. J Infect Dis 1995;171:751-4. [PubMed: 7876635]

56. Singh N, Curran MD, Rastogil AK, Middleton D, Sundar S. Diagnostic PCR with Leishmania donovani specificity using sequences from the variable region of kinetoplast minicircle DNA. Trop Med Int Health 1999;4:448-53. [PubMed: 10444321]

57. Pal S, Aggarwal G, Haldar A, Majumdar A, Majumdar HK, Duttagupta S. Diagnosis of symptomatic kala-azar by polymerase chain reaction using patient's blood. Med Sci Monit 2004;10:MT1-5. [PubMed: 14704640]

58. Maurya R, Singh RK, Kumar B, Salotra P, Rai M, Sundar S. Evaluation of PCR for diagnosis of Indian kala-azar and assessment of cure. J Clin Microbiol 2005;43:3038-41. [PubMed: 16000412]

59. Cruz I, Chicharro C, Nieto J, Bailo B, Canavate C, Figueras MC, et al. Comparison of new diagnostic tools for management of pediatric Mediterranean visceral leishmaniasis. J Clin Microbiol 2006;44:2343-7. [PubMed: 16825347]

60. Katakura K, Kawazu SI, Sanjyoba C, Naya T, Matsumoto Y, Ito M, et al. Leishmania mini-exon genes for molecular epidemiology of leishmaniasis in China and Ecuador. Tokai J Exp Clin Med 1998;23:393-9. [PubMed: 10622637]

61. Fisa R, Riera C, Ribera E, Gallego M, Portus M. A nested polymerase chain reaction for diagnosis and follow-up of human visceral leishmaniasis patients using blood samples. Trans R Soc Trop Med Hyg 2002;96(Suppl 1):S191-4. [PubMed: 12055837]

62. Islam MZ, Itoh M, Mirza R, Ahmed I, Ekram AR, Sarder AH, et al. Direct agglutination test with urine samples for the diagnosis of visceral leishmaniasis. Am J Trop Med Hyg 2004;70:78-82. [PubMed: 14971702]

63. Islam MZ, Itoh M, Shamsuzzaman SM, Mirza R, Matin F, Ahmed I, et al. Diagnosis of visceral leishmaniasis by enzyme-linked immunosorbent assay using urine samples. Clin Diagn Lab Immunol 2002;9:789-94. [PubMed: 12093674] 
Table 1

Reported sensitivities and specificities of different target using PCR protocols in the diagnosis of visceral leishmaniasis

\begin{tabular}{|c|c|c|c|c|}
\hline \multirow[t]{2}{*}{ Target (bp) for PCR } & \multicolumn{2}{|l|}{ Sensitivity (\%) } & \multirow[t]{2}{*}{ Specificity (\%) } & \multirow[t]{2}{*}{ Reported by } \\
\hline & Blood & BMA & & \\
\hline kDNA (nr): L. donovani & 90 & NR & 100 & Nuzum et al. 55 \\
\hline kDNA (204 bp): L. donovani & 82.3 & NR & 100 & Singh et al. 56 \\
\hline kDNA (600 bp): L. donovani & 96 & 100 & 96 & Salotra et al. 41 \\
\hline kDNA (790 bp): Leishmania species & 100 & 83 & 100 & Pal et al. 57 \\
\hline kDNA (600 bp): L. donovani & 99 & NR & 100 & Maurya et al. 58 \\
\hline SSU-rRNA (nr): Leishmania species & 70 & 100 & 100 & Osman et al. 39 \\
\hline SSU-rRNA n-PCR (358 bp): L. infantum & 95.4 & 100 & 100 & Cruz et al. ${ }^{42}$ \\
\hline SSU-rRNA & $\begin{array}{l}73.2 \text { by conventional PCR; } 83.9 \text { by ELISA } \\
\text { PCR }\end{array}$ & NR & 87.2 & De Doncker et al. ${ }^{32}$ \\
\hline SSU-rRNA n-PCR (358 bp): L. infantum & 79 & 100 & 100 & Cruz et al. 59 \\
\hline SSU-rRNA real-time: L. infantum & 100 & NR & 100 & Bossolasco et al. ${ }^{43}$ \\
\hline SSU-rRNA oligoC Test & 93.2 & NR & 98.3 & Deborggraeve et al. ${ }^{5}$ \\
\hline MedRNA (180 bp): L. donovani & 96.8 & NR & 100 & Adhya et al. 40 \\
\hline PCR mini-exon gene (450 bp): L. donovani & NR & 83.3 & 100 & Katakura et al. 60 \\
\hline n-PCR (100 bp): L. infantum & 100 & 100 & 100 & Fisa et al. 61 \\
\hline
\end{tabular}

BMA: bone marrow aspirate; bp: base pair; kDNA: kinetoplast DNA; medRNA: multicopy mini-exon RNA; n-PCR: nested PCR; NR: not reported; SSU-rRNA: small subunit ribosomal RNA. 

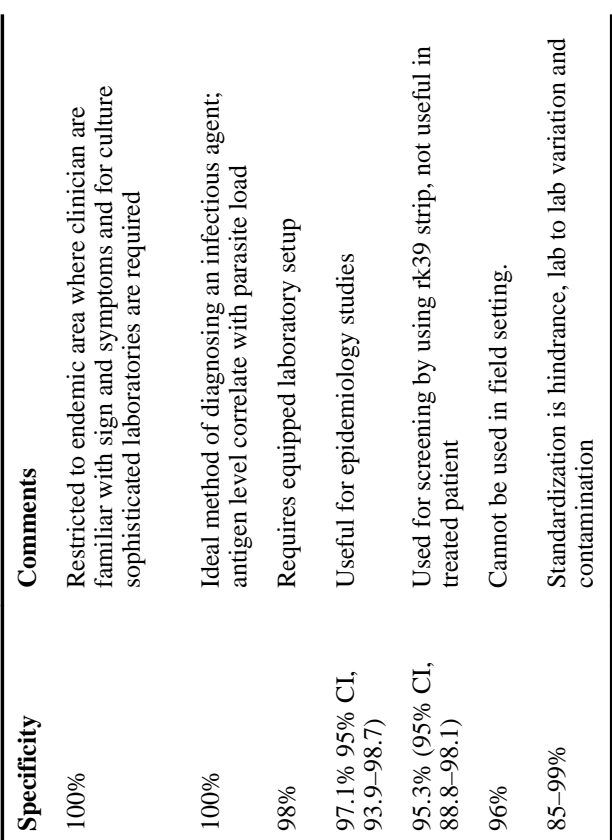

䒜

N
$\frac{0}{0}$
$\frac{0}{\leftarrow}$

aे

के है

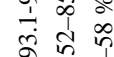

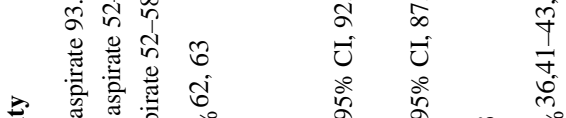

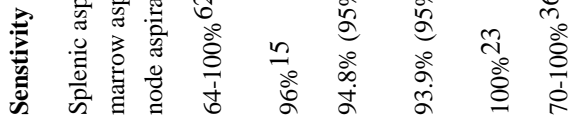

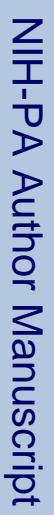

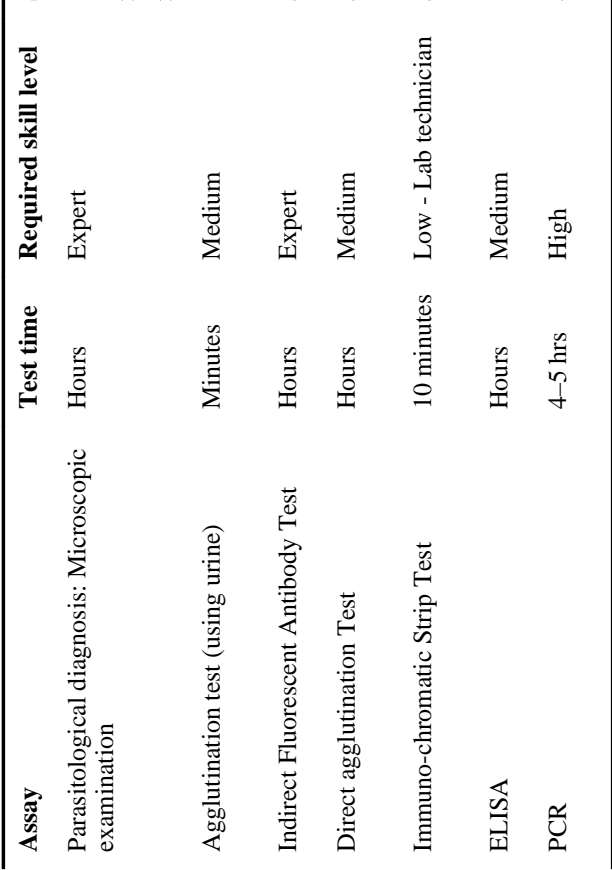

Trans R Soc Trop Med Hyg. Author manuscript; available in PMC 2012 January 1. 